\title{
EDITORIAL
}

\section{Join World Birth Defects Day} Pediatric Research (2019) 86:3-4; https://doi.org/10.1038/s41390-
019-0392-x

World Birth Defects Day aims to change the lives of people living with birth defects (congenital anomalies) and to promote primary prevention wherever possible. Annually, an estimated 3-6\% of infants or nearly 8 million worldwide are born with a serious birth defect, and more than $90 \%$ of these infants are born in low and middle income countries. ${ }^{1}$

Serious birth defects are structural or functional abnormalities, mostly originating during the first trimester of pregnancy, all of which likely have some degree of genetic and/or environmental causes. Some are amenable to primary prevention; ${ }^{1}$ all could benefit from improved health and developmental services. Birth defects have a major health impact. Of the affected infants born annually, at least 1 in 3 die before age 5 and another 1 in 3 survive with significant disability. Birth defects disproportionately affect those born in low and middle income countries, where an affected newborn is at much higher risk of dying than a similarly affected newborn in a high-income country. ${ }^{1,2}$ Despite this high toll globally, it has been difficult to obtain support for birth defects surveillance, research, primary prevention, and access to care.

Health organizations have voiced their concern and their calls to action. The 63rd World Health Assembly Resolution ${ }^{3}$ recognized that children with birth defects have been left behind in policies, programs, research, and funding. In 2010, United Nations member states agreed to raise awareness for birth defects as a cause of child morbidity and mortality. The Sustainable Development Goals (SDG) adopted by the United Nations in 2015 aim to ensure healthy lives and promote wellbeing for all children ${ }^{4}$ and has as one of its goals (goal 3 , target 3.2) to end preventable deaths of newborns and children under5 years of age by 2030. For that to occur, prevention of birth defects and care of children with birth defects must be part of the global child health agenda.

Given the lack of birth defects data and monitoring programs in many low and middle income countries, the true impact of birth defects remains elusive. ${ }^{5}$ Birth defects in most of the world are an invisible tragedy. There is also the misconception that birth defects cannot be prevented, which is incorrect. Although not all, many birth defects can actually be prevented by simple preconception health strategies, better counseling, and reducing environmental threats - with the added benefit of improving the overall health of women and couples. Examples include improving nutrition, enhancing periconceptional folic acid consumption, avoiding well-known teratogens, screening, and treating diabetes and other chronic disease, as well as reducing unhealthy lifestyle factors, among others.

Many countries are behind in addressing birth defects in their health agendas because these conditions are frequently overlooked in global reports related to improving maternal, newborn, and child health. Increasing the inclusion of birth defects in these health agendas is the challenge at the foundation of World Birth Defects Day. This annual event is promoted by a partnership of many organizations (www.worldbirthdefectsday.org/partners). World Birth Defects Day, observed since 2015 every year on March 3, has quickly blossomed into a global phenomenon that includes a wide range of activities conducted by partner organizations. These activities include local events, developing and disseminating educational messages and materials on birth defects, and the extensive use of social media. In 2019, World Birth Defects Day is supported by 170 participating organizations around the world.

World Birth Defects Day is designed to raise awareness about birth defects, reduce stigma, and increase opportunities for prevention. Specific goals are to promote: (a) more and improved birth defects surveillance programs everywhere, (b) better access to care, and (c) more research to find causes, in particular, modifiable causes. To effectively address gaps in birth defects surveillance, prevention, care, and research, individuals and organizations working in reproductive, maternal, newborn, child, and adolescent health must join forces. Other organizations, like universities and other educational and cultural sites, professional associations, and mass media can be important partners to spread the messages. In our global society, people with birth defects must not be left behind. The World Birth Defects Day is an opportunity to promote awareness and action locally and globally. We invite all individuals and organizations to join World Birth Defects Day (www.worldbirthdefectsday.org) movement to raise awareness about the impact of birth defects on families and communities.

\section{ACKNOWLEDGEMENTS}

The authors would like to thank Dr. Cara Mai from the Centers of Disease Control and Prevention for her constructive criticism of the manuscript.

\section{ADDITIONAL INFORMATION}

Competing interests: The authors declare no conflict of interest.

Publisher's note: Springer Nature remains neutral with regard to jurisdictional claims in published maps and institutional affiliations.

Boris Groisman (D) ${ }^{1}$, Eva Bermejo-Sánchez ${ }^{2}$, Paul A. Romitti ${ }^{3}$, Lorenzo D. Botto ${ }^{4}$, Marcia L. Feldkamp ${ }^{4}$, Salimah R. Walani ${ }^{5}$ and Pierpaolo Mastroiacovo ${ }^{6}$

${ }^{7}$ National Network of Congenital Anomalies of Argentina (RENAC), National Center of Medical Genetics, National Administration of Health Laboratories and Institutes, National Ministry of Health, Buenos Aires, Argentina; ${ }^{2}$ ECEMC (Spanish Collaborative Study of Congenital Malformations), Centro de Investigación sobre Anomalías Congénitas (CIAC), Institute of Rare Diseases Research (IIER), Instituto de Salud Carlos III (ISCIII), Madrid, Spain; ${ }^{3}$ Department of Epidemiology, College of Public Health, University of lowa, lowa City, lowa, USA; ${ }^{4}$ Division of Medical Genetics, Department of Pediatrics, University of Utah School of Medicine, Salt Lake City, Utah, USA;

${ }^{5}$ Global Health Programs, March of Dimes, Arlington, Virginia, USA and ${ }^{6}$ Alessandra Lisi International Centre on Birth Defects and Prematurity- $I C B D$, Rome, Italy

Correspondence: Boris Groisman (bgroisman@gmail.com) 


\section{REFERENCES}

1. Christianson A., Howson C., Modell B. March of Dimes Global Report on Birth Defects: The Hidden Toll of Dying and Disabled Children. March of Dimes Birth Defects Foundation, White Plains, NY, 2006.

2. Darmstadt G. L.; Participant Working Group of the Dar es Salaam Seventh International Conference on Birth Defects and Disabilities in the Developing World, et al. Prevention of Congenital Disorders and Care of Affected Children: A Consensus Statement. JAMA Pediatr. 170, 790-793 (2016).

3. World Health Organization. 63rd World Health Assembly. Agenda Item 11.7. Birth Defects. http://apps.who.int/gb/ebwha/pdf_files/WHA63/A63_R17-en.pdf (Accessed 1 Oct 2018).

4. Every Woman Every Child. Sustainable Development Goals. The Global Strategy for Women's, Children's and Adolescents' Health (2016-2030). 2015. http://www.who. int/life-course/partners/global-strategy/globalstrategyreport2016-2030-lowres.pdf (Accessed 1 Oct 2018).

5. Zaganjor, I. et al. Describing the prevalence of neural tube defects worldwide: a systematic literature review. PLOS ONE 11, e0151586 (2016). 